\title{
CHANGES IN ACRYLAMIDE MONOMER CONTENT DURING COMPOSTING OF DAIRY PROCESSING SLUDGE
}

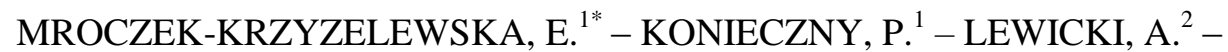 \\ WAŚKIEWICZ, A. ${ }^{3}-\mathrm{JANCZAK} \mathrm{D}^{2}$ \\ ${ }^{I}$ Department of Food Quality Management, Poznan University of Life Sciences, Wojska \\ Polskiego 71, PL-60-625 Poznan, Poland \\ (phone: +48618487319 ) \\ ${ }^{2}$ Institute of Biosystems Engineering, Poznan University of Life Sciences, Wojska Polskiego 28, \\ PL-60-637 Poznan, Poland \\ (phone: +48618466062 ) \\ ${ }^{3}$ Department of Chemistry, Poznan University of Life Sciences, Wojska Polskiego 75, PL-60-625 \\ Poznan, Poland \\ (phone: +48618487841$)$ \\ *Corresponding author \\ e-mail:emroczek@up.poznan.pl \\ (Received $7^{\text {th }}$ May 2016; accepted $9^{\text {th }}$ Jan 2017)
}

\begin{abstract}
This paper focused on the results of an experiment involving sewage sludge drawn from a typical dairy processing plant after application of polyacrylamide (PAM) flocculant in an approximate dosage of $3.5 \mathrm{~kg} \mathrm{Mg}^{-1}$ dry matter for dewatering and subsequently taken for aerobic fermentation in a lab-scale bioreactor with a capacity of $120 \mathrm{dm}^{3}$ within 31 days. Since it can not be ruled out that such sewage sludge will be used as a good soil fertilizer for edible plants, e.g. vegetables, the concentration of neurotoxic and carcinogenic residual acrylamide monomer (AMD) was monitored throughout the composting process. Analysis of AMD was conducted using the HPLC method for compost samples taken after the $1^{\text {st }}$ day of the experiment, on the $10^{\text {th }}$ day and on the last $31^{\text {st }}$ day of the experiment. The results obtained from the composting process with measurement of temperature and air flow intensity indicate that aerobic composting resulted in a significant reduction of the AMD content in the compost, up to $23 \%$ of the initial value. It appears to be the case that intensive processes of biochemical degradation during aerobic fermentation of sludge from the dairy processing plant significantly reduces the threat of residual monomers being released into the environment from a polyacrylamide applied as a chemical sludge conditioner.
\end{abstract}

Keywords: AMD, PAM (polyacrylamide),flocculants, aerobic fermentation process, composted mixture

\section{Introduction}

Thanks to supporting wastewater treatment processes using various kinds of chemical reagents, including coagulants and flocculants in different nodes of technological installations for cleaning municipal and industrial wastewater, large quantities of sewage sludge are produced (Vanerkar et al., 2013). Raw sludge is difficult to use and dispose of not only due to its large mass, but generally its undesirable texture, and the fact that it easily ferments. Selecting the process of sewage sludge management frequently requires an individual approach and should remain in close relation to the particular conditions of the plant (Green and Stott, 2001).

In the case of sludge collected during wastewater treatment processes we deal with features that often prevent it from being used in agriculture, for example, an increased amounts of heavy metals and other highly toxic inorganic or organic chemicals. 
However, sewage sludge from food processing can be used as fertilizer if there were appropriate technical means and if the value of the subsequent products were to exceed the cost of reprocessing. After adequate stabilization, such sludge is suitable for improving soil used for agricultural purposes and for efficient land reclamation of degraded soils (European Commission, 2001; Adani, at al., 2004; Ruden, 2004; Szwedziak, 2006). The high content of organic matter and the significant amount of macro- and microelements has a positive effect on the physico-chemical properties of the soil and demonstrate a soil-forming impact stimulating the accumulation of humic substances in the environment. The methods applied for this purpose include methane fermentation and sludge stabilization by composting. Sewage sludge can be composted, especially after the addition of a variety of structural materials. The purpose of this is to increase the permeability by weight, to facilitate optimum moisture enrichment of the sludge with an additional carbon source and provide an optimal $\mathrm{C}: \mathrm{N}$ ratio ( $\mathrm{Su}$ and Wong, 2003, Adani, 2004; Szwedziak, 2006; Rebollido et al., 2008).

In view of the common usage of polyacrylamide flocculants for thickening or dewatering raw sewage sludge, the key issue is to assess the risk that unwanted monomeric forms, which constitute the unpolymerized part of such a reagent, may be released into the environment. It is not explicitly excluded that the monomer acrylamide is also a transitional biodegradable polyacrylamide product, which can be hydrolyzed as a nitrogen (i.e. amide hydrolysis) or carbon (i.e. carbon chain hydrolysis) source during the anaerobic process (Mroczek et al., 2015). The monomer acrylamide is characterized by proven, high carcinogenic and neurotoxic activity (Chico-Galdo at al., 2006; Mustafa at al., 2008 Wang et al., 2010). Available literature sources focus primarily on analyzing the problem of acrylamide in foods subjected to intense heat treatment. Studies have also been conducted to analyze this threat from a different perspective, and these studies are therefore related to the application of polyacrylamides in the soil environment as hydrogels or as components of organic fertilizers (Lee and Shoda, 2008; Wan et al., 2011; Dai et al, 2013, Dai et al, 2014; Uma Rani et al., 2013 Di Maria et al., 2014). Despite the strict legal requirements in this area, the practice of sourcing plant materials, especially vegetables, from soil fertilized with stabilized sewage sludge, and thus the food use of such materials still cannot be clearly excluded (Class et al, 2007). Scientists' queries concern the degradation mechanism for polyacrylamides, their chemical reactivity and especially the risks of the mobility and accumulation of residual monomers in edible plants (Friedman, 2003). Thus far the results of the authors' own research confirmed that in both lettuce cultivation in hydroponic conditions and its cultivation in peat, the contamination of plant tissue with such residues can occur (Mroczek et al., 2014, 2015). At the same time, other studies (Mroczek et al., 2016) demonstrated that the methane fermentation process used for the stabilization of industrial sludge, which is thickened with polyacrylamide flocculant, significantly reduces acrylamide monomer content in post-ferment, which is recommended for organic fertilization. Together with the continuation of the above research, in this paper, a laboratory bioreactor was used for preparation, in an attempt to determine the extent of changes in acrylamide monomer content in sediment from the dairy processing plant and under the conditions of aerobic fermentation. 


\section{Materials and methods}

\section{Materials}

The material tested was PAM-treated sludge collected from a local dairy processing plant producing typical milk waste and cleaning wastewater from the facilities of the factory. The sludge samples were obtained from a dairy effluent treatment plant characterized by a flow approximately $600 \mathrm{~m}^{3} /$ day and a population equivalent about 23,500. The characteristics of the influent wastewater of this plant, which produces drinking milk, yoghurt, kefir and quark and working without a whey protein recovery system, were as follows: $\mathrm{pH}$ was 5.5 , total COD was $5000 \mathrm{mg} / \mathrm{L}$, total nitrogen was 30 $\mathrm{mg} / \mathrm{L}$ and total phosphorus was $7.1 \mathrm{mg} / \mathrm{L}$. The chemicals used during wastewater and sludge treatment included alum, iron chloride, iron sulphate and selected PAM flocculants. Following the technological procedure, a highly charged, very high molecular weight cationic product in the form of an emulsion with a residual acrylamide monomer content below $1000 \mathrm{ppm}$ was employed for sludge thickening in an approximate dosage of $3.5 \mathrm{~kg} \mathrm{Mg}^{-1}$ dry matter (DM). Wheat straw was used as a cosubstrate for the composting process and as a structural material.

In order to simulate the process taking place in a full-scale composting pale and to measure the parameters of such a process, a special composting chamber was constructed (Fig. 1) (Czekała et al., 2016).

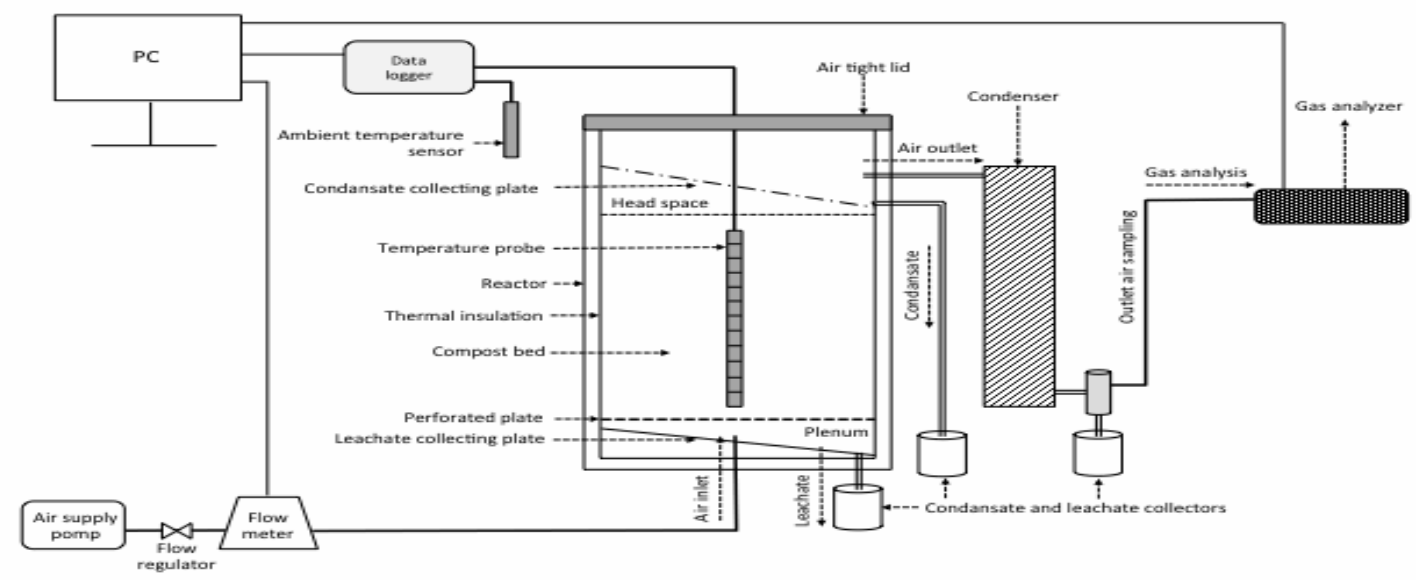

Figure 1. Design of chamber composting bioreactor used to compost dairy processing sludge and straw mixture.

After many experiments, it was discovered that the minimum chamber volume needs to be greater than $120 \mathrm{dm}^{3}$. Thus, the dimensions of the research reactors made of Plexiglas were 50x50x73 cm, which gave a volume of more than $180 \mathrm{dm}^{3}$. All the reactors were covered with a $10-\mathrm{cm}$ layer of Styrofoam to simulate thermal isolation (in the field the top of the composting substrate pale performs the role of an isolation layer).

To analyze the temperature of the substrates, a special measurement set-up was constructed. This consisted of nine sensors situated on a plastic stick at 5-cm intervals. The stick was then placed vertically in the middle of the reactor and connected to a computer which collected the data every eight hours. Thanks to such a technique, it was possible to verify temperature changes not only in time but also on different layers of the composting mixture being analyzed. 
Other important data collected from the reactors were the speed and volume of air pumped into the chambers from below. To measure the air flow, Brooks rotameter (GT $1355 / \mathrm{D}$ with a range of $0.43-4.3 \mathrm{ln} / \mathrm{min}$ ) was used. In order to be sure of the air volume pumped into the reactor, a gas meter was connected to the system right after the gas pump. Afterwards, when gas flowed through the chamber, the air volume was examined twice a day.

\section{Solid samples}

During the experiment, the following standard methodology established by Polish Norms (PN) was used: for dry matter (TS - Total Solids) PN-75 C-04616/01, pH-PN-90 C-04540/01 and conductivity PN-EN 27888:1999.

\section{Analysis of acrylamide monomer in digested dairy sludge and composting samples}

\section{Chemicals}

A standard of pure acrylamide ( $\geq 99.8 \%)$ and acetone (HPLC grade) were purchased from Sigma-Aldrich (St. Louis, MO, USA). Sodium dihydrogen phosphate and $o$ phosphoric acid were purchased from POCh (Gliwice, Poland). Water for the HPLC mobile phase and standard solutions was purified by a Milli-Q system (Milipore, Bedford, MA, USA).

\section{Sample preparation}

Acrylamide monomer was determined using three types of samples: dairy sludge, straw and a trial mixture of both substrates used in the aerobic fermentation experiment. The reactant mixture was subjected to one variant stabilised by aerobic fermentation conditions: composting. Substrates for fermentation were analysed by downloading them from the reactor three times in triplicate, at the start of the process (the first day of the experiment), during the process $\left(10^{\text {th }}\right.$ day) and at the end of the process $\left(31^{\text {st }}\right.$ day). Each $2 \mathrm{~g}$ sample was put into a plastic tube and the residual monomer was analysed using the same extraction procedure.

\section{Extraction of acrylamide}

Acrylamide was extracted from the samples using acetone: water (4:1, v/v) using 20 $\mathrm{ml}$ of solvent per $2 \mathrm{~g}$ of the sample, in accordance with Mroczek et al. (2014). After homogenisation (1 min.) (homogeniser H 500, Pol-Eco, Wodzislaw Sl, Poland), the samples were transferred to a thermostat controlled water bath at $60^{\circ} \mathrm{C}$ for $60 \mathrm{~min}$ (Memmert GmbH \& Co. KG, Schwabach, Germany). Next, the aqueous layer $(10 \mathrm{ml})$ was filtered through $0.45 \mu \mathrm{m}$ chromatographic filters (Chromafil, Macherey-Nagel, Germany) and collected for chromatographic analysis.

\section{Liquid chromatographic conditions}

Preparation of liquid chromatographic conditions was based on previous reports described by Michalak et al. (2013) and Wang et al. (2008, 2013) with own modifications. Chromatographic separation was performed by high performance liquid chromatography (HPLC), using a liquid chromatograph Waters 2695 (Waters, Milford, USA) equipped with a photodiode array detector (PAD model Waters 2996) set at 220 $\mathrm{nm}$. The column used was an Agilent PLRP-S 100A, $5 \mu \mathrm{m} 150$ x $4.6 \mathrm{~mm}$ (Agilent 
Technologies, Santa Clara, USA). Empower ${ }^{\mathrm{TM}} 1$ software was used for data processing. A sodium dihydrogen phosphate $(0.1 \mathrm{M}$ in water) solution adjusted to $\mathrm{pH} 3.0$ with $o$ phosphoric acid, after filtration through a $0.45 \mu \mathrm{m} H V$ membrane (Milipore, Bedford, MA, USA), was used as the mobile phase with a flow rate of $0.8 \mathrm{ml} \mathrm{min}^{-1}$. The mode of the HPLC instrument was isocratic with an injection volume of $10 \mu 1$. Standard stock solutions $\left(1.0 \mathrm{mg} \mathrm{ml}^{-1}\right)$ were prepared by dissolving $10 \mathrm{mg}$ of acrylamide in $10 \mathrm{ml}$ Milli-Q water and stored at $4^{\circ} \mathrm{C}$ until further use. All working solutions were prepared daily by serial dilution in Milli-Q water. The acrylamide detection limit was $1.0 \mathrm{ng} \mathrm{g}^{-1}$. Positive results (on the basis of retention time) were confirmed by HPLC analysis and compared with the relevant calibration curve (the correlation coefficient for acrylamide was 0.9967).

\section{Statistical analysis}

Tests were performed in triplicate, and the significance of the results was tested by ANOVA analyses. $\mathrm{P}<0.05$ was considered to be statistically significant.

\section{Results and discussion}

After anaerobic treatment, aerobic composting is the preferred method of neutralizing sewage sludge usually mixed with different structural materials in a suitable proportion to obtain a $\mathrm{C}: \mathrm{N}$ ratio between 20 and 30 in the compost. The parameters influencing the composting process include: the temperature of composting $\left(55-60^{\circ} \mathrm{C}\right)$, moisture composting masses $(40-60 \%)$, aeration intensity $\left(90-160 \mathrm{~m}^{3} / \mathrm{t} \cdot \mathrm{h}\right)$ and the duration time of composting process (< 4 weeks) ( Kosobudzki et al., 2000; Jiang, 2011). Dach (2010) reported that it is very difficult to obtain a proper $\mathrm{C}: \mathrm{N}$ ratio in composting sewage sludge since typical sludge contains even 4-5\% nitrogen in dry matter, and in consequence, the $\mathrm{C}: \mathrm{N}$ ratio for raw sludge is often below 10 . In this study, co-composting of commercially dewatered dairy processing sludge using a commercially made polyacrylamide (PAM) based flocculant was performed in a chamber bio-reactor. The sludge, which was previously described (Mroczek et al., 2016), comprised flocculated solids recovered from dairy wastewater treatment as a spade-able solid with an approximate moisture content of $75 \%$ and fat and protein contents of about 35\% and 15\%, respectively. The proportions of the substrate prepared for the composting process and selected parameters are illustrated by the data in Table 1 .

Table 1. Main ingredients of mixture composted in the lab scale experiment.

\begin{tabular}{|l|c|c|c|c|c|}
\hline & $\begin{array}{c}\text { wheat straw } \\
{[\mathrm{kg}]}\end{array}$ & $\begin{array}{c}\text { dairy sludge } \\
{[\mathrm{kg}]}\end{array}$ & $\mathrm{C}: \mathrm{N}$ ratio & $\mathrm{pH}[-]$ & $\begin{array}{c}\text { Conductivity } \\
{\left[\mathrm{mS} \cdot \mathrm{cm}^{-1}\right]}\end{array}$ \\
\hline Mixture & 7.60 & 26.00 & 11,6 & 8.0 & 0.78 \\
\hline
\end{tabular}

The proportion of dairy processing sludge and wheat straw incorporated in a mixture is likely to be limited by the porosity of the final mix and the ability of the mixing equipment to mix evenly and break up clumps of solids. Porosity can also be affected by varying other bulking agents, for example when fats are incorporated (Dai et al., 
2015). In our present study, mixture composition did not appear to inhibit the composting process, even at a lower rate of aeration.

\section{Temperature and oxygen concentration profiles}

All substrates prepared in the proportions mentioned above were homogenized and placed in the composting chamber, following which the air pump was started. Fig. 2 shows the air flow in the composting chamber.

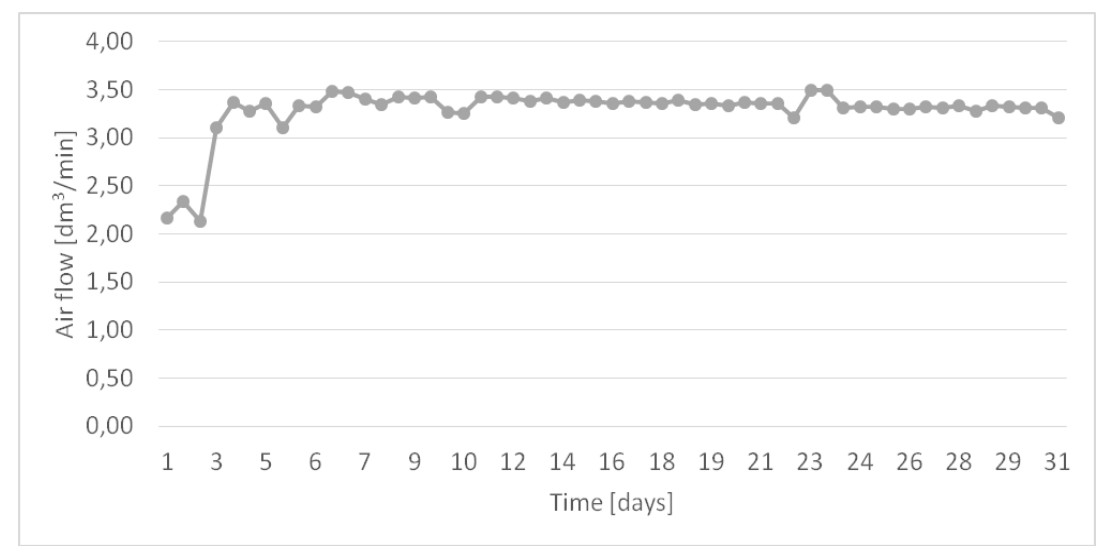

Figure 2. Air flow profile at various stages of composting.

There seems to be a strong correlation between the air flow and oxygen concentration (Fig. 3).

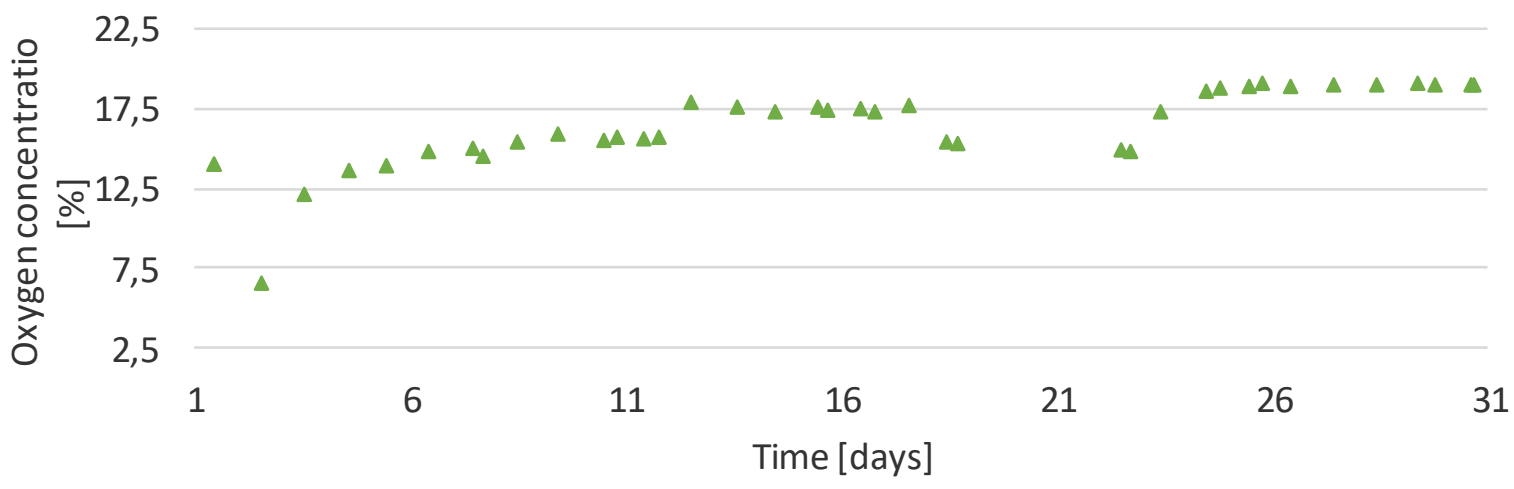

Figure 3. Oxygen concentration with composting period.

Owing to the fact that the composting process requires an oxygen concentration higher than $5 \%$, the air flow was increased from $2.2 \mathrm{dm}^{3} / \mathrm{min}$ to $3.5 \mathrm{dm}^{3} / \mathrm{min}$, since it had been noticed that the initial air flow of $2.2 \mathrm{dm}^{3} / \mathrm{min}$ was not sufficient to provide an oxygen concentration at the required level.

During the composting process, the temperature in the chamber was measured at nine depths from 0 to $40 \mathrm{~cm}$ at $5-\mathrm{cm}$ intervals Fig. 4 shows the temperature determined by the sensor placed in the middle of each chamber - at $20 \mathrm{~cm}$ ). 


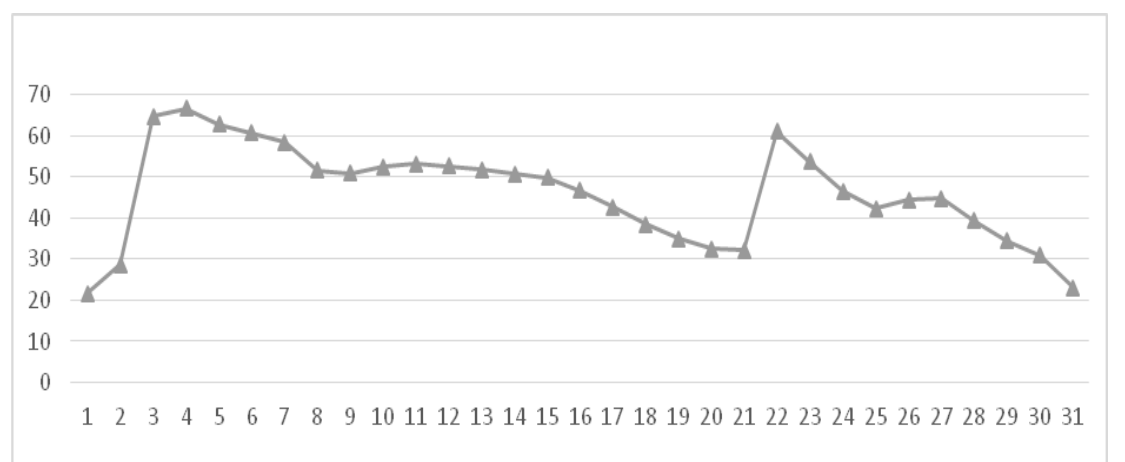

Figure 4. Temperature changes in composed sewage sludge mixture.

Table 2. Temperature distribution during the composting process.

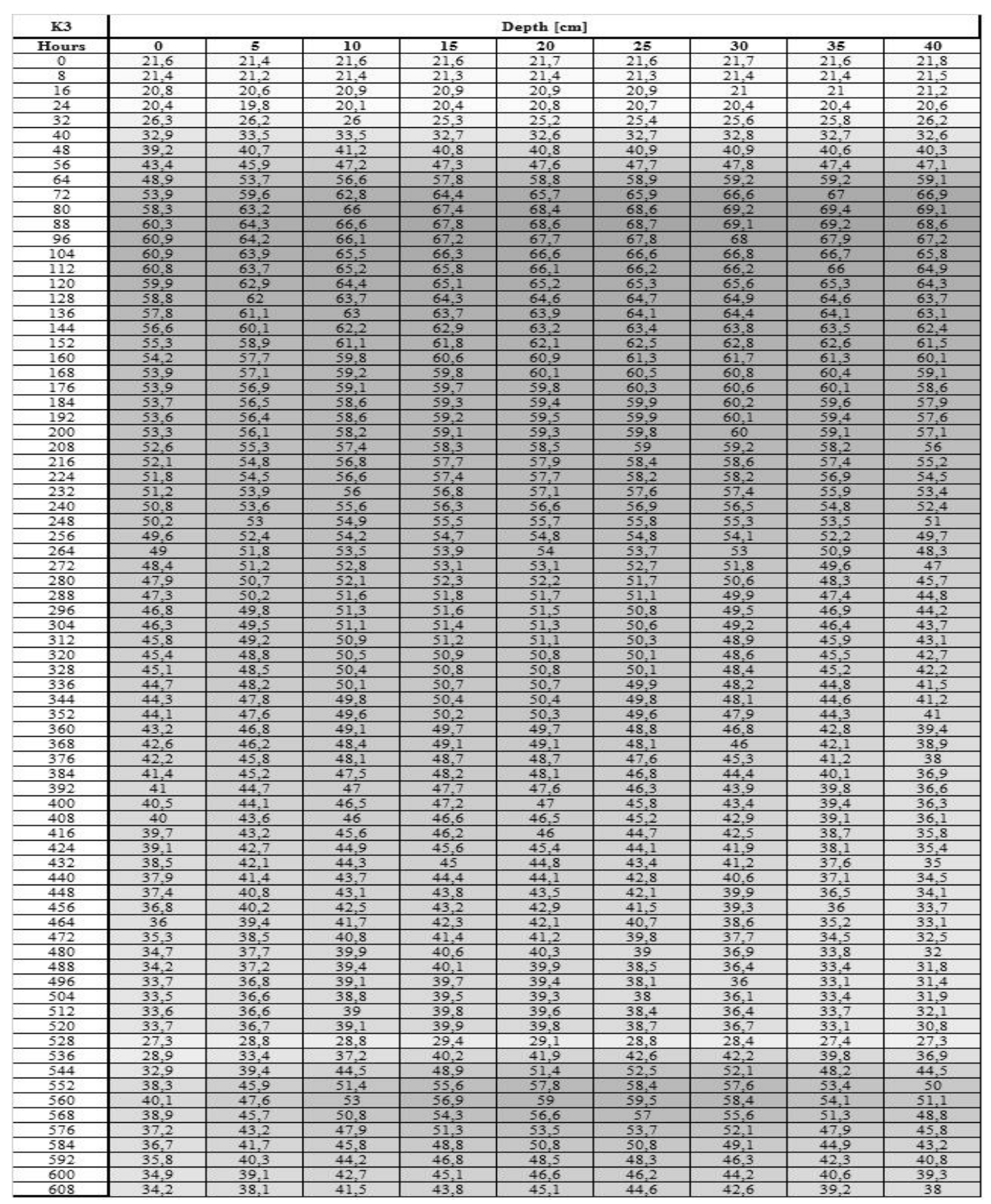


It is worth noting that at the $528^{\text {th }}$ hour of the process $\left(21^{\text {st }}\right.$ day), the temperature decreased rapidly and then increased by almost $30^{\circ} \mathrm{C}$ within two days. This situation was caused by mixing intervention - a method widely used in large-scale composting and processing by special machines. This technique serves to improve the structure of a composting pale by creating air pores, enabling oxygen to penetrate a pale easily. As a result of mixing, temperature increases rapidly. Although this temperature rise lasts much shorter than the initial one, it can sometimes reach again the thermophilic values. For better visualization of temperature distribution in the composting chamber, a Table 2 was prepared.

It presents the changes in temperature over time at every level of the composting material measured. There was a need for high-temperature substrate hygienization during the process because a temperature exceeding $60^{\circ} \mathrm{C}$ was maintained for more than six days (Boniecki et al., 2013).

\section{Determination of acrylamide monomer content}

The running of the experiment confirmed the possibility of monitoring and determining the monomer content in the sediment matrices generated by the food industry and in the substrate matrix stabilised by aerobic fermentation technology using high performance liquid chromatography (HPLC).

Analysis of acrylamide monomer content was conducted in the substrates used for the aerobic fermentation process: in the dairy sludge and in the straw (Table 3).

Table 3. The initial content of acrylamide monomer $( \pm S D)$ in main compost substrates.

\begin{tabular}{|c|c|}
\hline Substrate & $\begin{array}{c}\text { The content of acrylamide monomer } \\
{\left[\mathbf{m g ~ k g}^{-1}\right]}\end{array}$ \\
\hline Dairy sludge & $64,0 \pm 0.5$ \\
\hline Straw & nd \\
\hline
\end{tabular}

nd - none determined

The results demonstrated that the inoculum used for the experiment was free of AMD, while the dairy sludge contained $64 \mathrm{mg} \mathrm{kg}^{-1}$ in structure. These results confirm that the only source of acrylamide monomer in the experiment is sludge obtained from the dairy.

Analysis of AMD was conducted for sediment samples taken successively after the first day of the experiment, the $10^{\text {th }}$ day of the experiment and on the last day of the study to assess the impact of aerobic fermentation on the changes in the content of AMD in the composted mixture (Table 4).

Table 4. Changes of acrylamide monomer content in composted sewage sludge mixture ( mean values $\div S D$ ).

\begin{tabular}{|l|c|c|c|}
\hline \multirow{2}{*}{ Parameter } & \multicolumn{3}{|c|}{ AMD content $\left[\mathbf{m g ~ k g}^{-\mathbf{1}}\right]$} \\
\cline { 2 - 4 } & $1^{\text {st }}$ day & $10^{\text {th }}$ day & $31^{\text {st }}$ day \\
\hline & $9,0^{\mathrm{a}} \pm 0,3$ & $3,0^{\mathrm{b}} \pm 0,2$ & $2,0^{\mathrm{c}} \pm 0,1$ \\
\hline
\end{tabular}

$\mathrm{a}, \mathrm{b}, \mathrm{c}$ - mean values, designated by small letters, are statistically significantly different at $\mathrm{p} \leq 0.05$. 
Subsequently, for aerobic fermentation on the first day of the experiment, the level of AMD was approximately $9 \mathrm{mg} \mathrm{kg}^{-1}$, followed by $3 \mathrm{mg} \mathrm{kg}^{-1}$ on the $10^{\text {th }}$ day of the process, and $2 \mathrm{mg} \mathrm{kg}^{-1}$ on the final day of the study.

During the composting process, most of the reduction in acrylamide occurred during the first stage of the process. It seems that due to a changing microbial population and its activity, the degradation process speeds up and the breakdown of substrate organic matter leads into a residue consumed as a carbon and nitrogen source. Based on the results obtained during the composting process under conditions described, approximately $77 \%$ of the initial content of acrylamide monomer disappeared within 31 days. Furthermore, preliminary studies (Mroczek et al., 2016) also indicated that the process of methane fermentation continues regardless of the effect of temperature on AMD degradation in dairy sludge. The degree of acrylamide monomer reduction for thermophilic fermentation is $100 \%$, while for mesophilic fermentation it is $91 \%$. Similarly, biodegradation and removal of polyacrylamide by anaerobic hydrolysis during waste-activated sludge fermentation has been reported recently by Dai et al. (2015). Shanker (1990), Nawaz et al. (1993), Yu et al. (2015), Lina (2013) reported that acrylamide decomposition under model conditions was caused by populations of Pseudomonas sp. and Xanthomonas maltophilia.. It is worth pointing out that in a consortium of various microorganisms taking part in the aerobic composting of organic wastes, Pseudomonas sp bacteria activity is also one of most important factors for efficient hydrolysis of composted substrate (Grula, 1994; Ziemiński and Frac, 2012; Costa, 2014). An efficient detoxification and rapid biological degradation of toxic pollutant acrylamide was observed using also a Stenotrophomonas acidaminiphila bacterium isolated from the soil (Lakshmikandan et al., 2014). The bacterial strain isolated from paper mill effluent and identified as Gram negative, diplobacilli Moraxella osloensis MSU11 demonstrated a potential to degrade the acrylamide present in the environment (Jebasingh et al., 2013). Many studies have been carried out on the fate of acrylamide monomer following the application of polyacrylamide (PAM) to cropland (Castle et al., 1991; Castle et al., 1993; Loren at al., 1999; Friedman, 2003; Tareke, 2004). To understand the underlying mechanisms of the biological hydrolysis of PAM, some authors suggested very complicated metabolic pathways with respect to the enzymes (Bavernik et al., 1996; Dai et al., 2016).

Generally, it is clear that organic waste in the form of sludge should only be managed in an environmentally sound manner. Due to the fact that, as in the case of sludge from food processing wastewater installations, organic waste is often recommended for agricultural purposes, and especially for organic fertilization, there is still a potential risk of transferring and accumulating residual acrylamide monomer from polyacrylamide along the food chain where humans are the final users (Mroczek et al. 2014). Further studies focused on this problem are necessary.

\section{Conclusions}

The research proved the usefulness of a new kind of temperature sensor. Temperature analysis in the entire lab chamber allows the composting process to be controlled in a much more effective way. Moreover, it gives indirect information concerning the structure of the composting layer. Wherever the structure of the composting material is too packed to provide an optimal aeration temperature, the sensors will indicate that the temperature in this fragment differs from that in other parts 
of the composting layer. Another advantage of these sensors' location is the possibility of good visualization of the temperature distribution. This provides an opportunity to monitor the influence of weather conditions in large-scale composting processes and react appropriately to these changes (by mixing the composting layer or creating a thicker layer of composting mass).

The results obtained confirm that the technology of compost production based on aerobic fermentation affects the biodegradability of acrylamide monomer contained in dairy sludge. In practice, this means that aerobic fermentation technology reduces the risk of residual acrylamide monomer migrating to plants.

Acknowledgements. This paper was produced as a result of the project entitled "Technologies of methane emission reduction from animal production in the context of GHG reduction" financed by the Polish Ministry of Science and Higher Education (contract number: N N313 271338; 2010-13).

\section{REFERENCES}

[1] Adani, F., Tambone, F., Gotti, G. (2004): Biostabilization of municipal solid waste-Waste Management 24: 775-793.

[2] Castle, L.A., Campos, M..J., Gilbert, J. (1991): Determination of acrylamide monomer in hydroponically grown tomato fruits by capillary gas chromatography-mass spectrometryJ. Sci. Food Agric. 54: 549-555.

[3] Castle, L.B. (1993): Determination of acrylamide monomer in mushroms grown on polyacrylamide gel-J. Agric. Food Chem. 41: 1261-1263.

[4] Chico- Galdo, V., Massart, C., Jin, L., Vanvooren, V., Caillet-Fauquet, P., Andry, G., Lothaire, P., Dequanter, D., Friedman, M., Van Sande, J. (2006): Acrylamide, an in vivo thyroid carcinogenic agent, induces DNA damage in rat thyroid cell lines and primary cultures-Molecular and Cellular Endocrinology 6-14.

[5] Costa, F., Quintelas, C., Tavares, T. (2014): An approach to the metabolic degradation of diethylketone (DEK) by Streptococcus equisimilis: Effect of DEK on the growth, biodegradation kinetics and efficiency-Ecol. Eng. 70: 183-188.

[6] Czekała, W., Malińska, K. Caceres, R., Janczak, D., Dach, J., Lewicki, A. (2016): Cocomposting of poultry manure mixtures amended with biochar - the effect of biochar on temperature and C-CO2 emission-Bioresource Technology 200: 921-92.

[7] Dai, X., Duan, N., Dong, B., Dai, L., (2013): High-solids anaerobic co-digestion of sewage sludge and food waste in comparison with mono digestions: stability and performance- Waste Manag. 33(2): 308-316.

[8] Dai, X., Luo, F., Yi, J., He, Q., Dong, B., (2014): Biodegradation of polyacrylamide by anaerobic digestion under mesophilic condition and its performance in actual dewatered sludge system-Bioresour. Technol. 153: 55-61.

[9] Di Maria, F., Sordi, A., Cirulli, G., Gigliotti, G., Massaccesi, L., Cucina, M. (2014): Cotreatment of fruit and vegetable waste in sludge digesters. An analysis of the relationship among bio-methane generation, process stability and digestate phytotoxicity-Waste Manag. 34(9):1603-1608.

[10] European Commission, (2001): Disposal and recycling routes for sewage sludge. Part 1 - Sludge use acceptance. ISBN 92-894-1798-6, 1-54.

[11] Friedman, M. (2003): Chemistry, biochemistry, and safety of acrylamide. A review-J. Agric. Food Chem. 51: 4504-4526.

[12] Green, VS., Stott, DE. (2001): Polyacrylamide: A review of the use, effectiveness, and cost of a soil erosion control amendment-In: Stott DE, Mohtar RH and Steinhardt GC 
(eds), Selected papers from the 10th International Soil Conservation Organization Meeting.

[13] Grula, M., Huang, M.L., Sewell, G. (1994): Interactions of certain polyacrylamides with soil bacteria-Soil Sci. 158: 291-300.

[14] Jebasingh Emmanuel Joshua, S., Lakshmikandan, M., Rajesh, R.P., Raja, P. (2013): Biodegradation of acrylamide and purification of acrylamidase from newly isolated bacterium Moraxella osloensis MSU11-International Biodeterioration \& Biodegradation, Volume 85: 120-125.

[15] Lakshmikandan, M., Sivaraman, S., Elaiya, Raja, S., Vasanthakumar, P., Rajesh, R.P., Sowparthani, K., Emmanuel Joshua Jebasingh, S. (2014): Biodegradation of acrylamide by acrylamidase from Stenotrophomonas acidaminiphila MSU12 and analysis of degradation products by MALDI-TOF and HPLC-International Biodeterioration \& Biodegradation94: 214-221.

[16] Lee, H., Shoda, M. (2008): Stimulation of anaerobic digestion of thickened sewage sludge by iron-rich sludge produced by the fenton method-J. Biosci. Bioeng. 106(1): 107-110.

[17] Lina, H., Yuc, C., Chen, Z. (2013): Aerobic and anaerobic biodegradation of TNT by newly isolated Bacillus mycoides-Ecol. Eng. 52: 270-277.

[18] Loren, S., Fikry, F., Frank, W., Lentz, D., Sojka, E. (1999): Analysis of residual acrylamide in field crops-J. Chromatographic Sci. 37: 240-244.

[19] Michalak, , Gujska, E, Kuncewicz, A. (2013): RP-HPLC-DAD studies on acrylamide in cereal-based baby foods. J Food Compos Anal. 32(1): 68-73.

[20] Mroczek, E., Konieczny, P., Kleiber, T., Waśkiewicz, A. (2014): Response of hydroponically grown head lettuce on residual monomer from polyacrylamide-Food Additives \& Contaminants - Part A 31(8): 1399-1405.

[21] Mroczek, E., Konieczny, P., Kleiber, T., Waśkiewicz, A. (2015): Effect of residual monomer from polyacrylamide on head lettuce grown in peat substrate-Food Additives \& Contaminants - Part A 32(12): 2113-2119.

[22] Mroczek, E., Konieczny, P., Lewicki, A., Waśkiewicz, A., Dach J. (2016): Preliminary study of acrylamide monomer decomposition during methane fermentation of dairy waster sludge-Journal of Environmental Sciences http://dx.doi.org/10.1016/j.jes.2015.12.016

[23] Mustafa, A., Kamal-Eldin, A., Petersson, E. V., Andersson, R., Aman, P. (2008): Effect of extraction $\mathrm{pH}$ on acrylamide content in fresh and stored rye crisp bread-J. Food Comp. Anal. 21: 351-355.

[24] Nawaz, M.S., Franklin, W., Cerniglia, C.E. (1993): Degradation of acrylamide by immobilized cells of a Pseudomonas sp. and Xanthomonas maltophilia-Can. J. Microbiol. 39(2): 207-212.

[25] Rebollido, et al. (2008): Microbail populations during composting process of organic fraction of municipal solid waste-Applied Ecology and Environmental Research 6(3): 6167.

[26] Ruden, C. (2004): Acrylamide and cancer risk-expert risk assessments and the public debate-Food Chem. Toxicol. 42: 335-349.

[27] Shanker, R., Ramakrishna, C., Seth, P., (1990): Microbial degradation of acrylamide monomer-Arch. Microbiol.154: 192-198.

[28] Su, D.C., Wong, J.W.C. (2003): Chemical speciation and phytoavailability of $\mathrm{Zn}, \mathrm{Cu}, \mathrm{Ni}$ and $\mathrm{Cd}$ in soil amended with fly ash-stabilized sewage sludge-Environment International. 29: 895-900.

[29] Szwedziak, K. (2006): Charakterystyka osadów ściekowych i rolnicze wykorzystanieInżynieria Rolnicza 4: 297-302. 
[30] Tareke, E., Rydberg, P., Karlsson, P., Eriksson, S., Törnqvist, M. (2002): Analysis of acrylamide, a carcinogen formed in heated foodstuffs-J. Agric. Food Chem. 50(17): 49985006.

[31] Uma Rani, R., Adish Kumar, S., Kaliappan, S., Yeom, I., Rajesh Banu, J. (2013): Impacts of microwave pretreatments on the semi-continuous anaerobic digestion of dairy waste activated sludge-Waste Manag. 33(5): 1119-1127.

[32] Vanerkar, A.P., Satyanarayan, S., Satyanarayan, S. (2013): Treatment of food processing industry wastewater by coagulation/flocculation process-Inter. J. Chem. Phys. Sci. 2: 6372 .

[33] Wan, C., Zhou, Q., Fu, G., Li, Y. (2011): Semi-continuous anaerobic co-digestion of thickened waste activated sludge and fat, oil and grease-Waste Manag. 31(8): 1752-1758.

[34] Wang, H., Lee, A.W.M., Shuanga, S., Choi, M.M.F. (2008): SPE/HPLC/UV studies on acrylamide in deep-fried flour-based indigenous Chinese foods-Microchem J. 89(2): 9097.

[35] Wang, R., McDaniel, L.P., Manjanatha, M.G., Shelton, S.D., Doerge, D.R., Mei, N. (2010): Mutagenicity of acrylamide and glycidamide in the testes of Big Blue MiceToxicol. Sci. 117(1): 72-80.

[36] Wang, H., Feng, F., Guo, Y., Shuang, S., Choi, M.M.F. (2013): HPLC-UV quantitative analysis of acrylamide in baked and deep-fried Chinese foods-J Food Compos Anal. 31(1): 7-31.

[37] Ziemiński, K., Frąc, M. (2012): Methane fermentation process as anaerobic digestion of biomass: Transformations, stages and microorganisms-Afr. J. Biotechnol. 11(18): 41274139.

[38] Yu, F., Fu, R., Xie, Y., Chen, W. (2015): Isolation and characterization of polyacrylamide-degrading bacteria from dewatered sludge-Int $\mathrm{J}$ Environ Res Public Health 12(4): 4214-30. 